\title{
Can multilayer perceptron ensembles model the ecological niche of freshwater fish species?
}

\author{
R. Muñoz-Mas ，F. Martínez-Capel , J.D. Alcaraz-Hernández , A.M. Mouton
}

\begin{abstract}
A B S T R A C T
The potential of Multilayer Perceptron (MLP) Ensembles to explore the ecology of freshwater fish species was tested by applying the technique to redfin barbel (Barbus haasi Mertens, 1925), an endemic and montane species that inhabits the North-East quadrant of the Iberian Peninsula. Two different MLP Ensembles were developed. The physical habitat model considered only abiotic variables, whereas the biotic model also included the density of the accompanying fish species and several invertebrate predictors. The results showed that MLP Ensembles may outperform single MLPs. Moreover, active selection of MLP candidates to create an optimal subset of MLPs can further improve model performance. The physical habitat model confirmed the redfin barbel preference for middle-to-upper river segments whereas the importance of depth confirms that redfin barbel prefers pool-type habitats. Although the biotic model showed higher uncertainty, it suggested that redfin barbel, European eel and the considered cyprinid species have similar habitat requirements. Due to its high predictive performance and its ability to deal with model uncertainty, the MLP Ensemble is a promising tool for ecological modelling or habitat suitability prediction in environmental flow assessment.
\end{abstract}

\section{Introduction}

Ecological models for the quantitative prediction of species distributions are key to understanding the realised niche of species and its implication for species conservation in relation to global change (Austin, 2007). Therefore, ecological models have increasingly received attention due to their wide management applications in the context of biogeography, conservation biology and climate change studies (Mouton et al., 2010). Many studies on ecological modelling have focused on explanation rather than prediction (Elith and Leathwick, 2009); however, differences in the life-history or in the gene flow of fish assemblages could result in different realised niches (Mouton et al., 2010). Abiotic factors, together with dispersal and biotic interactions, are often considered the three elements that shape the ecological niche by determining species distribution and abundance (Barve et al., 2011). However, ecological models have usually focused on abiotic factors only (Boulangeat et al., 2012), and very few studies in freshwater fish ecology have explicitly included biotic variables (Elith and Leathwick, 2009) to explore biotic interactions and consumer-resource dynamics (Soberón, 2007). The consideration of these three elements (i.e. abiotic, biotic and dispersal factors) do not allow for simple statistical analysis because the data collected often exhibit non-linear and complex data structures (Crisci et al, 2012). Consequently, there is a need for new and innovative approaches to understand the complex structure of living systems (Larocque et al., 2011).

Several sophisticated modelling techniques have been applied in the ecological modelling of fish species, ranging from linear to multivariate and machine learning techniques such as Artificial Neural Networks (ANN) (Brosse and Lek, 2000, Muñoz-Mas et al., 2014, Palialexis et al., 2011). The most popular ANN architecture has been the Multilayer Perceptron (MLP) paradigm because it is considered to be able to approximate any continuous function (Olden et al., 2008). Formerly, MLP was referred to as a 'black box' because it provided little explanatory insight into the relative influence of variables in the prediction process (Olden and Jackson, 2002). To date, an enormous effort has been made to develop methods that clarify variable importance and interactions (Gevrey et al., 2006; Lek et al., 1996; Olden and Jackson, 2002), and consequently, MLPs 

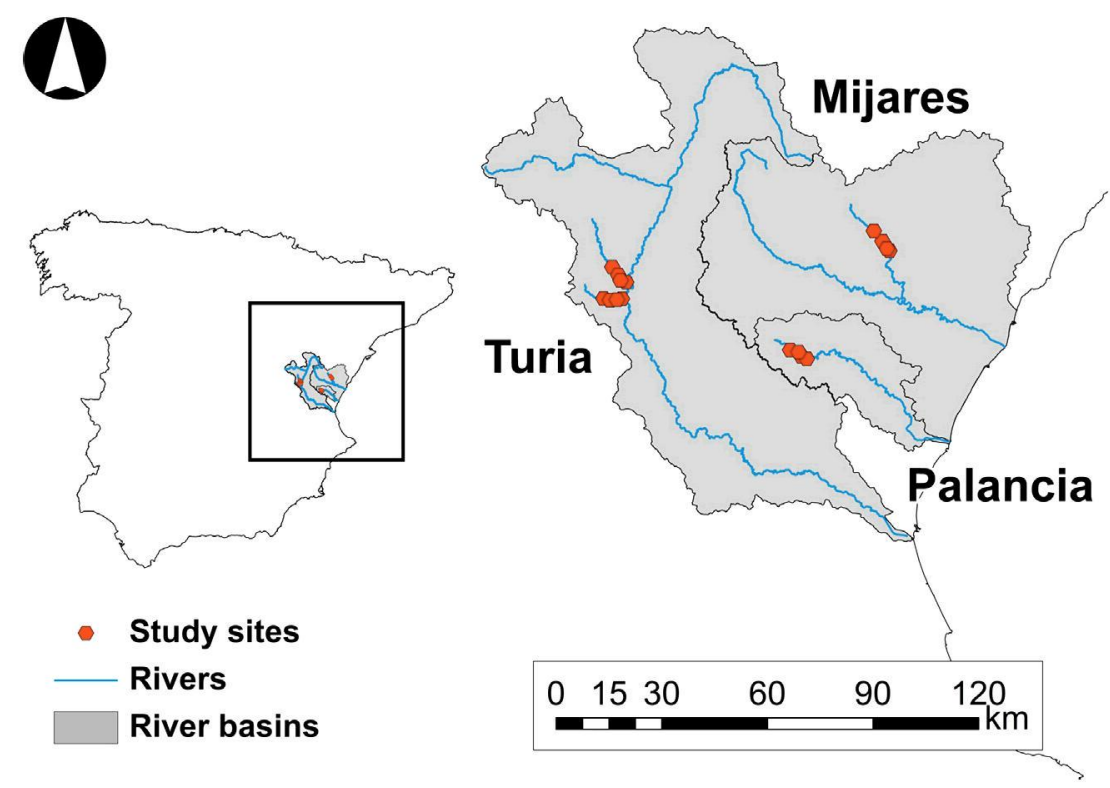

Fig. 1. Location of the target river basins in the Iberian Peninsula (left) and study sites in the Mijares, Palancia and Turia River basins.

should no longer be treated as 'black box' models (Özesmi et al., 2006).

There are several examples of single MLP applications in freshwater fish ecology (Park and Chon, 2007). For instance, MLPs have been successfully applied to model fish ecology through a broad range of ecosystems (Brosse and Lek, 2000; Gevrey et al., 2006; Kemp et al., 2007; Laffaille et al., 2003) and in some cases outperforming other statistical approaches (Baran et al., 1996; Lek et al., 1996). Despite those successful studies, it has been demonstrated that single models (e.g. a single MLP) do not necessarily perform consistently, resulting in divergent predictions (Buisson et al., 2010; Fukuda et al., 2011a, 2013). The use of model ensembles has been emphasised to overcome this phenomenon (Araúijo and New, 2007). The Multilayer Perceptron Ensemble (MLP Ensemble, Hansen and Salamon, 1990) has proven to be proficient in several areas of ecology (Palialexis et al., 2011; Watts and Worner, 2008), but has rarely been applied in freshwater ecosystems (Muñoz-Mas et al., 2014).

Fish communities in Mediterranean rivers are an interesting targets to develop these novel statistical approaches (Hopkins II and Burr, 2009), particularly communities dominated by cyprinids, as they are characterised by a high number of endemic species for which there is insufficient knowledge about their ecology (Ferreira et al., 2007). Furthermore, endemic species tend to facilitate a more robust analysis of species-environment relationships. In this paper, we focused on the redfin barbel(Barbus haasi Mertens, 1925), a rheophilic small barbel (maximum body-length $30 \mathrm{~cm}$ ) that is endemic to the Iberian Peninsula (Bianco, 1998) and categorised as vulnerable (Freyhof and Brooks, 2011). Their populations have decreased markedly, with pollution and the presence of exotic species being the main factors involved in the decline (Perea et al., 2011). Although redfin barbel has been the subject of numerous studies addressing its life-history, home-range, habitat preferences and the effects of pollutants (Aparicio and De Sostoa, 1999; Aparicio, 2002; Figuerola et al., 2012; Grossman and De Sostoa, 1994), a knowledge gap remains on the impact of biotic variables such as the density of accompanying fish species or invertebrate predictors in its ecological niche.

Therefore, the objective of this study was: (1) to test the proficiency of the MLP Ensembles to model the ecological niche of freshwater fish species and (2) to test whether biotic variables affect the distribution of redfin barbel. To achieve these aims using MLP
Ensembles, two different models of redfin barbel were developed. The first considered only physical habitat variables, the second included biotic and physical habitat variables.

\section{Materials and methods}

\subsection{Data collection}

The study was conducted at the meso-scale in every summer, between 2003 and 2006. The study sites were located in the headwaters of the Ebron and Vallanca Rivers (Turia River tributaries), the Palancia River and the Villahermosa River (Mijares River Tributary) (Fig. 1) which approximately correspond to the southern limits of redfin barbel distribution (Perea et al., 2011). All the study sites were in unregulated streams and therefore a wide flow range was sampled (i.e. from $0.02 \mathrm{~m}^{3} / \mathrm{s}$ to $1.84 \mathrm{~m}^{3} / \mathrm{s}$ ). For complete climatic description of the study area, see Alcaraz-Hernândez et al. (2011) and Mouton et al. (2011).

\subsubsection{Physical habitat survey}

The physical habitat was assessed in every $300 \mathrm{~m}$ reach using an adaptation of the Basinwide Visual Estimation Technique (Dolloff et al., 1993). The approach stratifies the study site by HydroMorphological Units (hereafter called HMUs) classified as: pools, glides, riffles, and rapids (see Alcaraz-Hernández et al., 2011 for further details). Once an HMU was categorised, its physical attributes were recorded. They were, length, average width, obtained from three cross-sections corresponding to $1 / 4,1 / 2$, and $3 / 4$ of the total length, mean depth (hereafter as depth), calculated from nine points corresponding to the measurements taken at each of the aforementioned cross-sections and the maximum depth, measured at the corresponding point. Percentage of shading over the channel, percentage of embeddedness, pieces of woody debris and percentage of the substrate types following a simplified classification from the American Geophysical Union (Martínez-Capel et al, 2009; Muñoz-Mas et al., 2012) were visually estimated and summarised in the substrate index (Mouton et al., 2011). In addition, the cover index (García de Jalón and Schmidt, 1995) was determined. This index characterises the available refuge due to caves, shading, substrate, submerged vegetation and water depth by assigning six scores from 0 (no refuge) to 5 (maximum score), and the weighted aggregation of these scores produces an index range from 0 to 10 . 
Table 1

Code, summary, units and description of the variables included in the MLP Ensemble models.

\begin{tabular}{|c|c|c|c|c|c|c|c|c|}
\hline Variable code & Min. & 1st Qu. & Median & Mean & 3rd Qu. & Max. & Units & Description \\
\hline River.Reach & 1 & 4 & 8 & 8.108 & 12 & 16 & - & Study site code \\
\hline Year & 2003 & 2004 & 2005 & 2005 & 2006 & 2006 & - & Date \\
\hline Meso.type & 1 & 2 & 3 & 2.95 & 4 & 4 & - & Mesohabitat type \\
\hline Meso.diversity & 0.2 & 0.62 & 0.7 & 0.68 & 0.76 & 0.99 & - & Reach mesohabitat diversity \\
\hline Length & 8.6 & 19.1 & 24.36 & 26.92 & 31.5 & 54.7 & $\mathrm{~m}$ & Length \\
\hline Width & 1.26 & 3.43 & 4.79 & 4.66 & 5.83 & 8.8 & $\mathrm{~m}$ & Width \\
\hline Depth & 0.04 & 0.22 & 0.32 & 0.35 & 0.46 & 0.79 & $\mathrm{~m}$ & Mean depth \\
\hline M.Depth & 0.15 & 0.43 & 0.63 & 0.64 & 0.83 & 1.23 & $\mathrm{~m}$ & Maximum depth \\
\hline Velocity & 0.01 & 0.09 & 0.24 & 0.3 & 0.42 & 1.06 & $\mathrm{~m} / \mathrm{s}$ & Mean flow velocity \\
\hline Substrate & 2.65 & 4.9 & 5.2 & 5.22 & 5.7 & 8 & - & Substrate index \\
\hline Embeddedness & 0 & 0 & 15 & 29.35 & 50 & 100 & $\%$ & $\%$ mud covering substrate \\
\hline Cover & 1 & 2.75 & 3.5 & 3.67 & 4.25 & 7.5 & - & Cover index \\
\hline Shadow & 0 & 20 & 60 & 54.95 & 85 & 100 & $\%$ & $\%$ shading \\
\hline Wood.debris & 0 & 0 & 0 & 0.01 & 0 & 0.16 & pieces $/ \mathrm{m}^{2}$ & Woody debris \\
\hline Elevation & 605 & 655 & 743 & 745.8 & 792 & 968 & m & Reach elevation above datum \\
\hline Slope & 0.01 & 0.01 & 0.01 & 0.02 & 0.02 & 0.04 & $\mathrm{~m} / \mathrm{m}$ & Reach slope \\
\hline D.redfin & 0 & 0 & 0 & 2.61 & 2.66 & 31.22 & ind. $/ 100 \mathrm{~m}^{2}$ & Density of Barbus haasi \\
\hline D.b.trout & 0 & 1.32 & 4.48 & 11.19 & 16.12 & 86.47 & ind. $/ 100 \mathrm{~m}^{2}$ & Density of Salmo trutta \\
\hline D.eel & 0 & 0 & 0 & 0.9 & 0 & 20.74 & ind. $/ 100 \mathrm{~m}^{2}$ & Density of Anguilla anguilla \\
\hline D.r.trout & 0 & 0 & 0 & 3.64 & 2.18 & 42.58 & ind. $/ 100 \mathrm{~m}^{2}$ & Density of Oncorhynchus mykiss \\
\hline D.cyprinids & 0 & 0 & 0 & 12.31 & 11.09 & 198.3 & ind. $/ 100 \mathrm{~m}^{2}$ & Cyprinids density \\
\hline Inv.density & 0 & 1930 & 4680 & 7910 & 9590 & 56,010 & ind. $/ \mathrm{m}^{2}$ & Invertebrates density \\
\hline Inv.richness & 0 & 16 & 19 & 18.55 & 22 & 34 & - & Invertebrates richness \\
\hline Inv.diversity & 0 & 0.34 & 0.41 & 0.39 & 0.46 & 0.56 & - & Invertebrates diversity \\
\hline Inv.biomass & 0 & 0 & 0.07 & 0.39 & 0.27 & 6.02 & $\mathrm{~g} / \mathrm{m}^{2}$ & Invertebrates biomass \\
\hline
\end{tabular}

Table 2

Fish community in the four rivers. The cyprinid fish community varied across rivers and was summarised in a single variable.

\begin{tabular}{llll}
\hline Ebron & Vallanca & Palancia & Villahermosa \\
\hline Salmo trutta & Salmo trutta & Salmo trutta & Salmo trutta \\
Oncorhynchus mykiss & Oncorhynchus & Oncorhynchus & Oncorhynchus \\
Babus haasi & mykiss & mykiss & mykiss \\
Luciobarbus guiraonis & Babus haasi & Babus haasi & Babus haasi \\
Anguilla anguilla & Luciobarbus & Luciobarbus & Luciobarbus \\
& guiraonis & guiraonis & guiraonis \\
& Achondrostoma & Anguilla & Achondrostoma \\
& arcasii & anguilla & arcasii \\
& & & Squalius \\
& & & valentimis \\
& & & Anguilla anguilla \\
\hline
\end{tabular}

The river flow was gauged in at least one cross-section using an electromagnetic current metre (Valeport ${ }^{\mathbb{B}}$ ), and flow velocity was calculated by dividing the flow by the average cross-section area. Elevation and slope were extracted from cartography in a geographic information system, whereas habitat variability was estimated with the Shannon-Weaver diversity index, taking into account the number of habitat types (i.e. number of pools, glides, riffles or rapids) from the visual stratification of each study site (Table 1).

\subsubsection{Biological survey}

The biological survey was undertaken by electrofishing, and all captured fish species were recorded. In each study site, one slow (i.e. pool or glide) and one fast (i.e. riffle or rapid) HMU were selected and surveyed (3-passes removal) after netting off the HMU. Due to a severe drought, some study sites were dry, resulting in 93 HMUs being sampled. Redfin barbel males are mature at approximately $45 \mathrm{~mm}$, while females are mature at $100 \mathrm{~mm}$ (Aparicio, 2002), and therefore it was regarded as conservative to consider all specimens larger than $45 \mathrm{~mm}$, resulting in a prevalence of 0.42 . No size restrictions were imposed on the remaining fish species, and thus all the individuals were considered in the data analysis. Since the fish community varied across streams, the cyprinid species were grouped in a single variable (Table 2), and following previous studies fish densities were $\log (x+1)$ transformed (Brosse and Lek, 2000; Fukuda et al., 2011b).

Benthic invertebrates were collected with a Hess sampler $\left(0.5 \mathrm{~m}^{2}\right)$ following the International Standard ISO 8265:1988, official version of the European Standard EN 29265 (January 1994). Samples were later identified to the lowest possible taxonomic level (predominantly at family level), sorted and counted to obtain the density of invertebrates. Specimens were dried in an oven at $65^{\circ} \mathrm{C}$ for $24 \mathrm{~h}$ and the dry residue was weighed to obtain invertebrate biomass. Finally, two additional predictors were derived: invertebrate richness (i.e. the sum of present taxa in each sample) and invertebrate diversity by applying the Shannon-Weaver diversity index based on the number of individuals per taxa at each sampled HMU (Table 1).

\subsection{Models' development}

The physical habitat and biotic models were developed by means of MLP Ensembles (Hansen and Salamon, 1990).

The development of the optimal MLP Ensembles followed the overproduce-and-choose approach. This approach consists of the generation of an initial large pool of MLP candidate classifiers (overproduce) whereas the second phase is devoted to select the best performing subset of MLPs (choose). The choose phase was performed by means of the step-forward algorithm. Thus, starting from every MLP candidate classifier the best complementary MLP candidate is iteratively searched until no improvement in the mean squared error (MSE) was achieved (Fig. 2A).

To render parsimonious models, the optimal input variables' subsets for both models were also selected by means of the stepforward algorithm. First, the best pair of input variables was determined by developing a MLP Ensemble for every uncorrelated pair following the aforementioned procedure and then this pair became the base for the following step forward variable selection. The algorithm continued until no more variables were available and the selected model was the one with the lowest number of variables and error. Finally, in order to rule out overfitting, we visually estimated differences between the distributions of the MSE based on the training and validation datasets of the selected MLPs (Fig. 2B). 


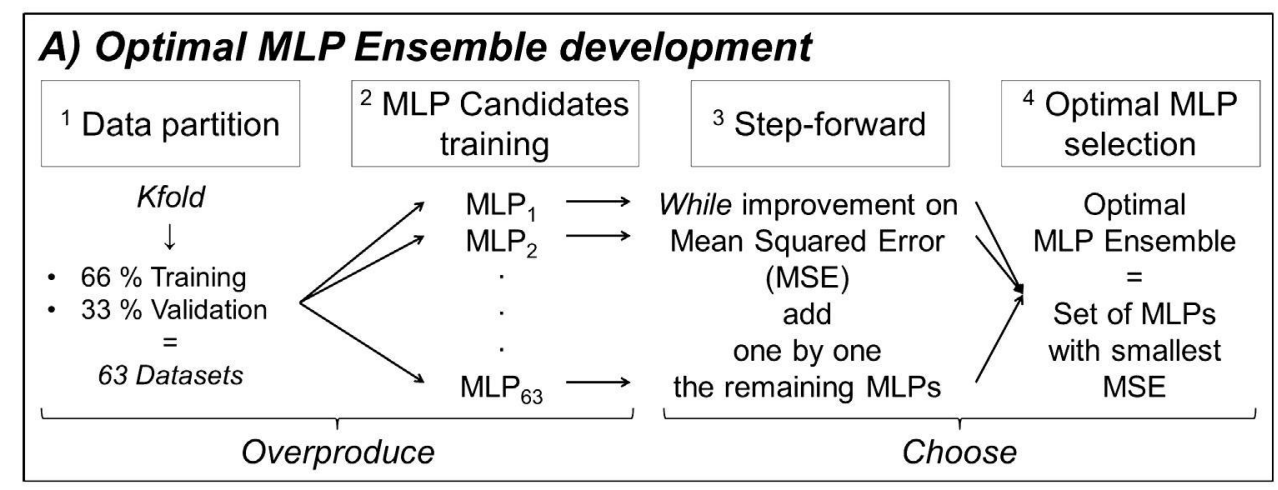

\begin{tabular}{|c|c|c|c|}
\hline \multicolumn{4}{|c|}{ B) Variable \& model selection } \\
\hline $\begin{array}{c}1 \text { Starting variables } \\
\text { selection }\end{array}$ & $\begin{array}{c}2 \text { Modified } \\
\text { step-forward }\end{array}$ & $\begin{array}{l}{ }^{3} \text { Parsimonious } \\
\text { model selection }\end{array}$ & $\begin{array}{l}{ }^{4} \text { Overfitting } \\
\text { inspection }\end{array}$ \\
\hline $\begin{array}{c}\text { Train a MLP } \\
\text { Ensemble } \\
\text { following A) for } \\
\text { every uncorrelated } \\
\text { pair of variables } \\
\downarrow \\
\text { Select the pair } \\
\text { with smallest MSE }\end{array}$ & $\begin{array}{c}\text { Add iteratively } \\
\text { one by one } \\
\text { all the remaining } \\
\text { uncorrelated variables } \\
\text { training for every } \\
\text { combination a MLP } \\
\text { Ensemble } \\
\text { following } \mathrm{A})\end{array}$ & $\begin{array}{l}\text { Select the MLP } \\
\text { Ensemble with } \\
\text { the lower number } \\
\text { of variables and } \\
\text { lower MSE }\end{array}$ & $\begin{array}{c}\text { Analysis of the } \\
\text { MSE committed } \\
\text { by every MLP on } \\
\text { the training and } \\
\text { validation } \\
\text { datasets of the } \\
\text { selected set of } \\
\text { MLPs }\end{array}$ \\
\hline
\end{tabular}

Fig. 2. Flowchart of the steps followed in the development of the physical habitat and biotic models.

\subsubsection{Multilayer Perceptron Ensemble development}

Building a MLP Ensemble involves training several individual models (MLPs) and combining them to produce aggregated predictions (Hansen and Salamon, 1990). The construction of the individual models (hereafter MLP candidates) was carried out in $R$ (R Development Core Team, 2012) with the package monmlp which optimises the model weights using the non-linear minimisation ( $\mathrm{nlm}$ ) routine (Cannon, 2012). The activation functions were the hyperbolic tangent and the linear transformation, while the number of nodes was restricted to improve generalisation (Özesmi et al., 2006) following Eq. (1):

$N_{\text {nodes }}=\max \left(\left\{1,\left\lfloor\frac{\text { number of variables }+1}{2}\right\rfloor\right\}\right)$

The aggregated forecast was determined by averaging the individual predictions of each selected model. Since model training depends on initial conditions, every MLP candidate was optimised five times with 500 iterations each.

Heterogeneity, or diversity, between MLP candidates is crucial because MLP Ensembles achieve better generalisation when models are complementary (Opitz, 1999). Several approaches allow for the construction of an MLP Ensemble with heterogeneous candidates, such as using different training datasets, architectures or learning methods (Brown et al., 2005). To increase heterogeneity among models, the database was divided in 63 different training and validation datasets corresponding to all possible combinations of $66 \%$ of the cases for training, and $33 \%$ for validation (i.e. following the $k$-fold approach). Consequently, 63 different MLP candidates were trained for every tested combination of input variables.

Originally the MLP Ensembles included all the developed models (Hansen and Salamon, 1990), but it was promptly demonstrated that active selection of the MLP candidates improved the final predictions (Opitz and Shavlik, 1996; Zhou et al., 2002). There are several methods to apply the overproduce-and-choose approach (Soares et al., 2013; Wang and Alhamdoosh, 2013; Yao and Xu,
2006; Zhou et al., 2002), but to our knowledge those sophisticated methods have not been coupled to a variable selection procedure. Consequently, we applied a step-forward selection of the MLP candidates which has been proved to perform similarly to more complex algorithms (Muñoz-Mas et al., 2014). Our step-forward selection was run starting from each of the 63 MLP candidates, searching for the best combination and stopping when no improvement was achieved. This was in contrast to the usual step-forward routine where the procedure would start from the best single model.

Since the optimal MLP Ensemble may not include all the MLP candidates, the observed performance could be affected by overfitting because the selected models may be trained only with some parts of the training database. Therefore the role of test data was twofold; first we applied an a priori regularisation method with the early stop regularisation (sensu Ludwig et al., 2014) by calculating the MSE on the validation dataset every 100 iterations of the nim routine and then we visually estimated for each selected MLP differences between the distributions of the MSE based on the training and validation datasets of all the selected MLPs. In the case of dissimilar distributions, the number of nodes and the number of iterations ran between calculations of the MSE on the validation dataset were readjusted.

To allow for the comparison with previous studies that either included all trained networks (Palialexis et al, 2011) or based the model selection on a ranking of the individual performances, including the top MLPs (Watts and Worner, 2008), the MSE of the best MLP candidate and of the MLP Ensemble Complete (i.e. the one without any models' selection) and then for the best five, ten and fifteen models were calculated and compared with our optimal MLP Ensembles.

\subsubsection{Variable selection}

To identify the most important variables shaping the ecological niche, for both models an input variable subset was selected based 
Physical habitat model

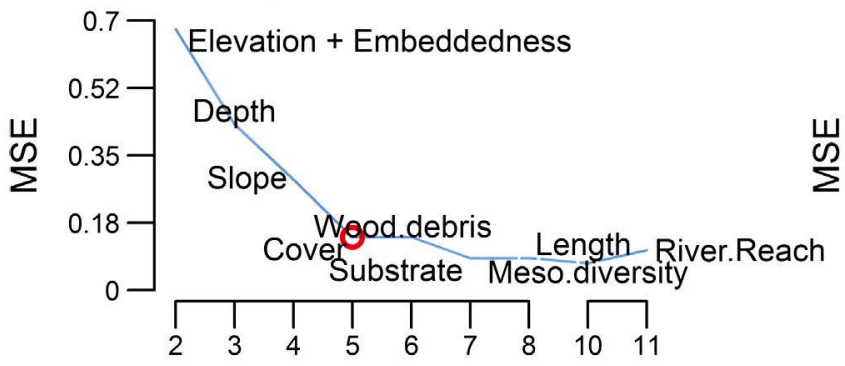

Number of Variables
Biotic model

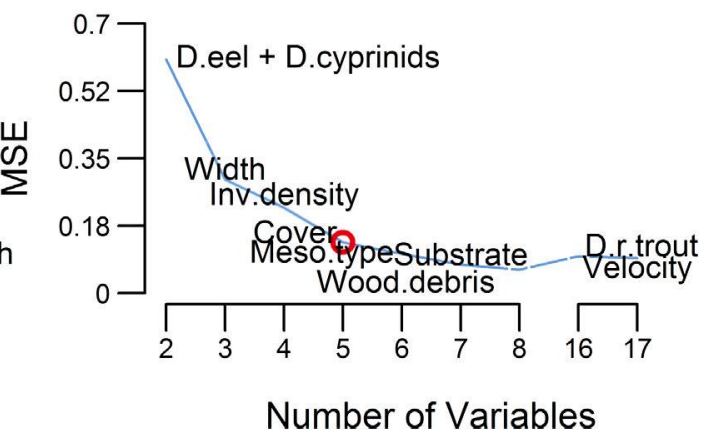

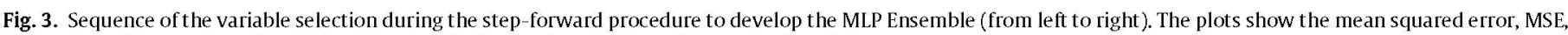
in function of the number of variables. The circle indicates the selection of the optimal model.

on the step-forward procedure because it has proven computationally efficient and tends to result in relatively small input variables' subsets (May et al., 2011). In contrast to some other approaches (e.g. generalised additive mixed models, Lin and Zhang, 1999) the MLP Ensemble approach does not specifically allow for the consideration of spatial or temporal autocorrelation among training data. To rule out any influence of study site and sampling year, they were included as input variables (Table 1). Their absence on the ultimate models would indicate their irrelevance, thus corroborating the properness of the data packing. In addition, to render parsimonious models, instead of the usual step-forward procedure that discontinues when no improvement is achieved, the procedure was sustained until no more variables were available. The performance of the best model (MLP Ensemble) and the number of variables considered at every iteration were rescaled between 0 and 1 ( 1 being optimal), with the optimal MLP Ensemble being the one that maximised the sum of both criteria. The step-forward procedure may fail to consider variable interactions and may depend on the variable that was selected first. To overcome this limitation, one model was developed for each pairwise combination of variables. The best pair of variables was selected as the starting set of variables in the step-forward procedure. Additionally, during the entire process, neither correlated $\left(r^{2}>0.5\right)$ nor collinear (variable inflation factor; vif $>5$ ) combinations of variables were considered. Since the input database was a combination of ordinal and continuous variables, the function hetcor in the package polycor (Fox, 2010) was used to calculate the variables' correlation (Appendix A1).

\subsection{Partial dependence plots and uncertainty analysis}

Model reliability and transparency is of major concern for ecological modelling (Austin, 2007; Guisan and Thuiller, 2005; Özesmi et al., 2006) and is fundamental when models are used with exploratory purposes. Therefore, to graphically characterise the relationship between the input variables and the predicted densities obtained by the optimal MLP Ensembles, partial dependence plots (Friedman, 2001) implemented in the package randomForests (Liaw and Wiener, 2002) were developed.

The importance of dealing with uncertainty has been stressed as a key challenge in ecological modelling (Larocque et al., 2011). Consequently, partial dependence plots were developed also for every model in the optimal MLP Ensemble, and the function densregion.normal in the package denstrip (Jackson, 2008) was used to visually inspect the uncertainty associated to the MLP aggregation in comparison with the input variable distribution.
Table 3

Mean squared error (MSE) of the best MLP candidate, the optimal MLP Ensemble the MLP Ensemble Complete (considering all MLPs; 63 ) and of the top five, top ten and top fifteen MLP. The amount of considered networks appears in brackets.

\begin{tabular}{lll}
\hline Model & Physical habitat model & Biotic model \\
\hline Best MLP candidate & $0.31(1)$ & $0.27(1)$ \\
Optimal MLP Ensemble & $0.14(15)$ & $0.13(8)$ \\
MLP Ensemble Complete & $0.95(63)$ & $0.31(63)$ \\
Top MLP - 1-5 & $0.23(5)$ & $0.19(5)$ \\
Top MLP - 1-10 & $0.21(10)$ & $0.18(10)$ \\
Top MLP - 1-15 & $0.18(15)$ & $0.18(15)$ \\
\hline
\end{tabular}

\section{Results}

\subsection{Training results}

The optimal physical habitat model included five variables (three nodes): elevation, embeddedness, depth, slope and cover (Fig. 3) with a maximum correlation of 0.33 and a variable inflation factor of 1.41. The optimal biotic model also included five variables (three nodes): density of eel, cyprinids' density, width, invertebrates' density and cover (Fig. 3) with a maximum correlation of 0.38 and variable inflation factor of 1.51. In addition, the spatiotemporal correlation was considered negligible since study site and sampling year were not selected as inputs in the ultimate models (i.e. the physical habitat and the biotic models).

Although the two models showed similar performance (i.e. similar values of the mean squared error, MSE) and the relatively large amount of zeros in the training dataset slightly biased their outputs, the biotic model slightly outperformed the physical habitat model with MSE of 0.12 and 0.13 respectively (Fig. 4 and Table 3). A complete description of the calculated MSE in every iteration is given in Appendix A2.

The physical habitat model selected 15 MLPs. Consequently, 15 training datasets and 15 validation datasets were involved in its development. Cross-evaluation (i.e. the evaluation of every training and validation dataset with every selected MLP candidate) showed that MSEs were distributed equally for the training and the validation datasets (Fig. 5), and therefore we considered the physical habitat model not overfitted. The biotic model selected eight MLPs, with eight training and validation datasets involved in the development of the selected MLPs. Likewise, the distribution of the training and validation MSE clearly overlapped, and therefore the biotic model was also considered not overfitted. The training datasets of the MLP candidates selected within the optimal MLP Ensembles are described in Appendix A3.

The best MLP candidate, the MLP Ensemble Complete (i.e. considering all sixty three MLPs) and the top five, top ten and top 

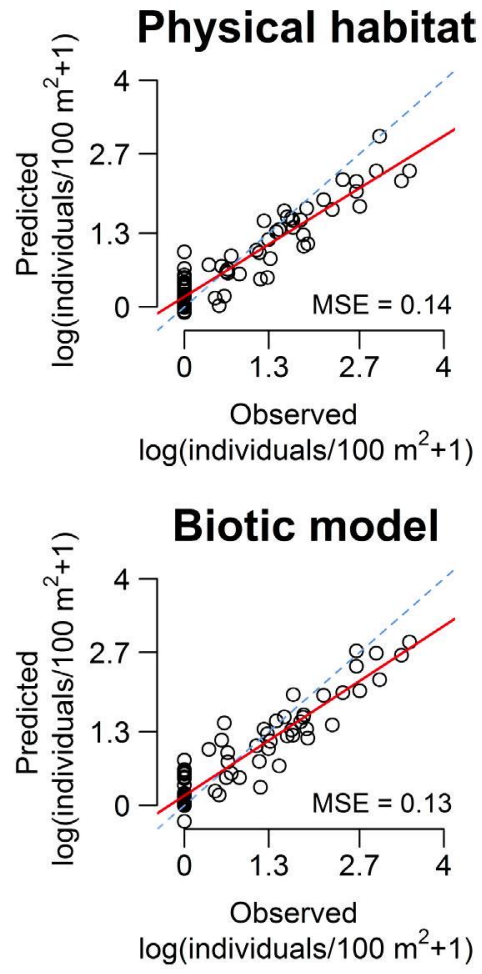

Fig. 4. Relation between the observed and predicted values of the optimal MLPs. The optimal physical habitat and biotic models show transformed output.

\section{Physical habitat}

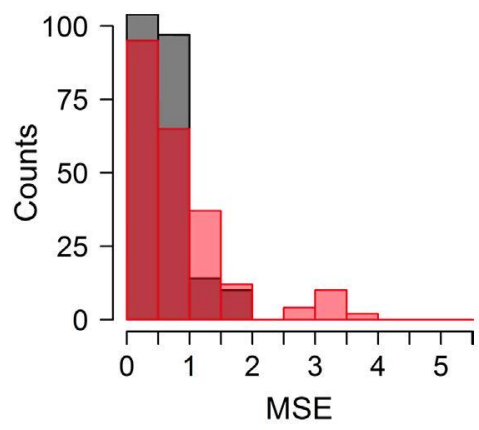

\section{Biotic model}

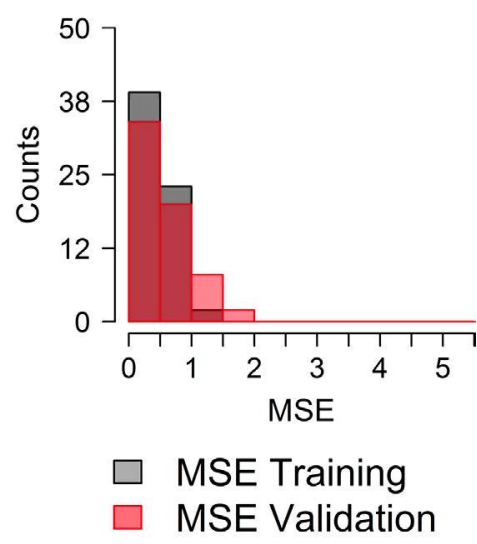

Fig. 5. Frequency analysis of the mean squared error (MSE) of the selected MLP candidates based on the corresponding training and validation datasets. fifteen MLPs yielded higher MSEs than the optimal MLP Ensembles. The highest difference appeared between the MLP Ensemble Complete and the optimal physical habitat model (Table 3).

\subsection{Partial dependence plots - physical habitat model}

The optimal physical habitat model showed a unimodal response between redfin barbel density and elevation, with a maximum density at $738 \mathrm{~m}$ above sea level. Embeddedness showed an almost flat trend but an exponential increase from $75 \%$ onwards. Depth showed a steep positive linear trend, thus suggesting the major impact among the selected variables, whereas slope and cover were negatively and almost linearly related to redfin barbel density. As expected, uncertainty was higher at the extremes of the variables' distributions and therefore trends at these extreme values could be unreliable (Fig. 6).

\subsection{Partial dependence plots - biotic model}

The optimal biotic model showed a positive linear relation between eel and redfin barbel densities. Cyprinids' density presented a unimodal response with the peak around 4 individuals $/ 100 \mathrm{~m}^{2}$. Width showed an almost positive linear influence on redfin barbel density whereas invertebrates' density presented a unimodal response inflecting at 21718 individuals $/ \mathrm{m}^{2}$. Likewise the physical habitat model cover presented a linear trend but with smaller uncertainty and slope. Uncertainty was higher than in the physical habitat model although it presented a similar pattern with the extreme values being more uncertain than the central part of the input variables' distributions (Fig. 7).

\section{Discussion}

\subsection{MLP Ensemble development}

Our results indicated that the MLP Ensemble paradigm can be considered proficient to model the ecological niche of freshwater fish species, in line with previous studies that modelled fish density with neural networks (Baran et al., 1996; Brosse and Lek, 2000: Laffaille et al., 2003). The presented optimal models also outperformed any single MLP, which agrees with previous research (Palialexis et al., 2011). We also demonstrated that active selection of MLP candidates to create an optimal subset can further improve MLP Ensembles' performance. This is consistent with Zhou's et al. (2002) statement that "many could be better than all". Moreover, our candidates' selection approach resulted in a better performance in contrast with the selection approach based on the individual performance (i.e. top five, ten and fifteen). We recommend this procedure in contrast to previous studies that selected the best subset based on the individual performance of the MLPs (Watts and Worner, 2008). However, our step-forward process is determined by the first selected model, and despite the fact that the procedure started from every single neural network, the possibility to get stuck at a local minimum exists. Therefore, untested combinations of models could outperform those obtained by the step-forward algorithm.

Genetic algorithms may overcome the aforementioned constraints (Soares et al., 2013; Wang and Alhamdoosh, 2013). There are successful applications of genetic algorithms in variable selection procedures (May et al., 2011; Olden et al., 2008) and also within the selection of optimal MLP Ensembles (Soares et al., 2013; Wang and Alhamdoosh, 2013). Although the use of genetic algorithms for both variable selection and MLP candidates' selection could exponentially increase the computation effort, this approach is certainly promising and should be the subject of future research. 
Elevation

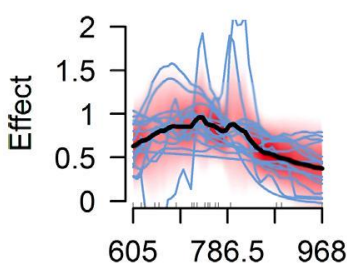

Elevation [m]

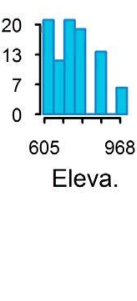

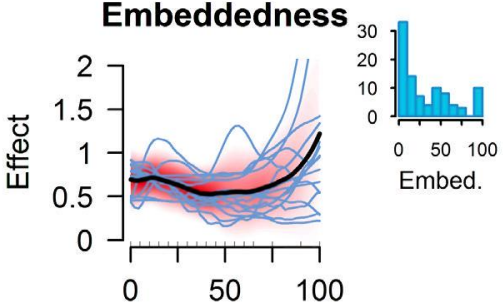

Embeddedness [\%]

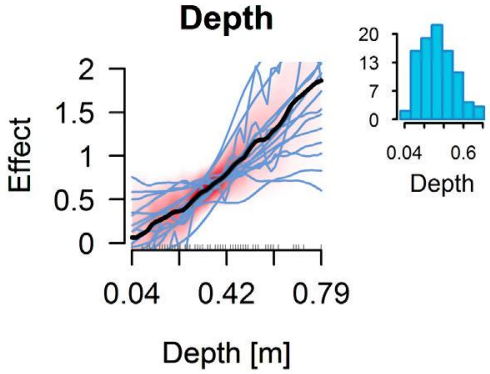

Depth $[\mathrm{m}]$
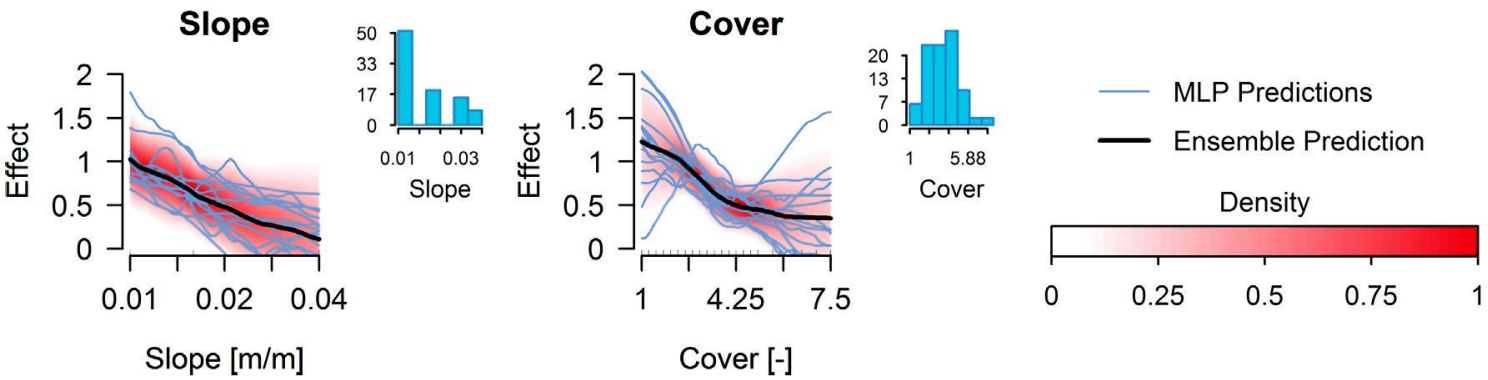

Slope $[\mathrm{m} / \mathrm{m}]$

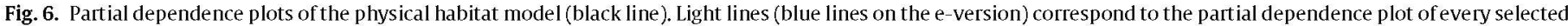

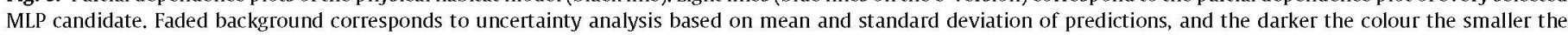
uncertainty.

The effect of the relatively large amount of zeros in the training dataset was a remarkable issue and slightly biasing models' outputs. There are specific techniques in count data modelling to deal with excess of zeros with either parametric (Mullahy, 1986; Lambert, 1992) and non-parametric (Liu and Chan, 2010) responses. Certainly the comparison of the capability of MLP Ensembles and these techniques in ecological modelling would be of interest, although these techniques by definition do not easily account for variable interactions and thus do not easily assure better performance. Nevertheless, our results were considered satisfactory since they provided an acceptable balance between model complexity, performance and computational effort, and they were devoted to explore rather than to predict fish density in further analysis.

\subsection{Ecological relevance of the physical habitat model}

The optimal physical habitat model included five variables: elevation, slope, depth, embeddedness and cover. Elevation is broadly accepted as a proximal predictor of temperature (Elith and Leathwick, 2009), and consequently we considered that it may reflect the effect of climate on redfin barbel distribution. Similarly, the negative trend of redfin barbell density versus slope agrees with its preference for middle-to-upper stream reaches of
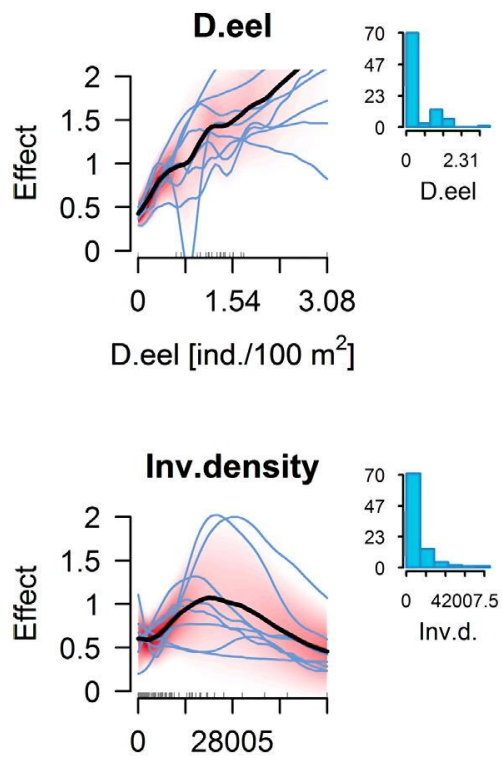

Inv.density [ind. $/ \mathrm{m}^{2}$ ]

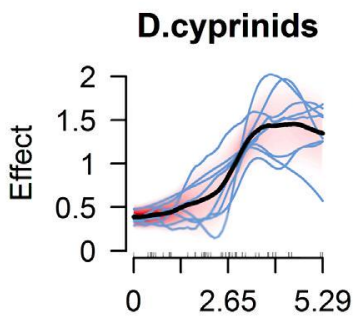

D.cyprinids [ind $/ 100 \mathrm{~m}^{2}$ ]

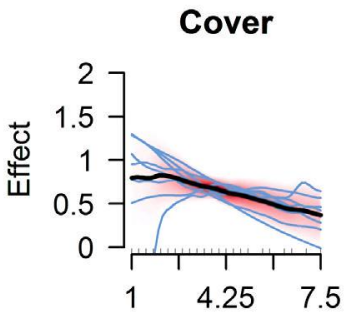

Cover [-]
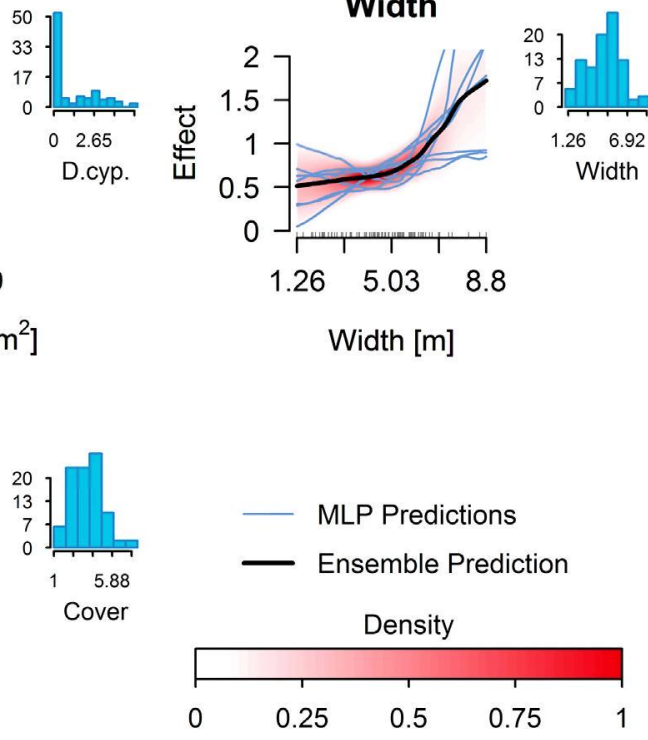

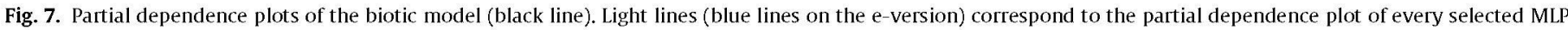

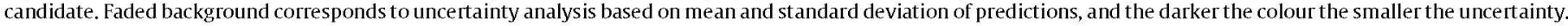


mountainous rivers (Perea et al., 2011). The positive impact of depth corresponds with previous studies that considered the redfin barbel a pool dweller (Aparicio and De Sostoa, 1999). Our results may also suggest the importance of backwaters or stagnated areas as resting habitats. This could also explain the positive relationship between redfin barbell density and embeddedness, since pool substrates are generally more embedded. Despite the negative relationship between cover and redfin barbel density in our study, some authors classified the redfin barbel as a cover-oriented fish (Grossman and De Sostoa, 1994). Aparicio (2002) reported the active use of cover in an ephemeral river but related its use to the absence of deep pools in this specific river, rather than to a redfin barbel preference for cover. Our study suggests that in more complex river systems with well-developed pool-riffle patterns, redfin barbel may tend to avoid excessive cover complexity.

\subsection{Ecological relevance of the biotic model}

In contrast to previous studies (Vezza et al., 2015; Watts and Worner, 2008) where the combination of physical habitat and biotic variables outperformed the model developed only with physical habitat variables, our biotic model did not significantly perform better than the physical habitat model. Moreover, uncertainty was higher in the biotic model, which underlines the previously reported complexity related to the assessment of biotic interactions (Leathwick and Austin, 2001). Although larger datasets may reduce this uncertainty, our study nevertheless suggests interesting and plausible relationships. In addition, the observed associations between biotic variables and red fin density agreed with the ecological gradient theory because responses were quasi-linear or unimodal (Austin, 2007).

The biotic model demonstrated a positive association between redfin barbel and European eel, which confirms the work of Laffaille et al. (2003). They modelled eel habitat suitability in a small coastal catchment with a single MLP. Eels were more abundant in deep and low flow shaded areas without aquatic vegetation (Laffaille et al., 2003). Such a pattern broadly concurs with the requirements of redfin barbel. Also the suggested relationship between redfin barbel and cyprinids corresponds with previous studies on the Iberian Peninsula that reported the presence of multi-species shoals as well as an overlap in microhabitat use (Martínez-Capel et al., 2009). Fish schooling benefits include the enhancement of hydrodynamics and the protection against predators (Landa, 1998). Moreover, similar positive interactions with cyprinid species have been reported for Iberian chub (Squalius pyrenaicus, Günther, 1868) and eastern Iberian barbel (Luciobarbus guiraonis, Steindachner, 1866) (Vezza et al., 2015). This indicates that restoration actions focused on redfin barbel could also result in habitat enhancement for other cyprinid species.

Although previous work positively correlated invertebrate density to fish density (Mas-Martí et al., 2010), our results show a maximal redfin barbel density at 21718 individuals $/ \mathrm{m}^{2}$. This could be related to food availability. However, the preferred prey invertebrates of redfin barbel (i.e. Chironomidae, Ephemeroptera and Trichoptera following Miranda et al., 2005) were strongly correlated with the invertebrate density applied in our model. Therefore, we attributed the avoidance of the higher invertebrate densities to a habitat correlation. Previous studies suggested that in Mediterranean rivers, with very unstable climatic conditions, riffles tend to host higher invertebrate density than pools (Bonada et al., 2006). Therefore the decrement of the partial dependence plot could be showing the necessity for larger depth rather than a preference for intermediate invertebrate densities. Nevertheless, the discrepancy between our results and the literature can also be a consequence of the applied model complexity (e.g. linear vs. non-linear models), and the impact of model complexity should be thoroughly analysed in further studies modelling the relationship between invertebrate and fish density. The biotic model also selected two physical habitat variables, cover index and width, and the relationship with cover index being similar to that shown in the physical habitat model. The positive association between redfin barbel density and width may be attributed to the negative correlation between width and elevation, in line with the aforementioned redfin barbel preference for middle-to-upper stream reaches, but with a slightly different response because the study encompassed four different rivers.

Although the biotic model appears to suggest interactions between redfin barbel and other species, significant positive or negative correlations between species does not imply a causative effect (Wisz et al., 2013).A simple correlation does not mandatorily correspond to any species interaction, neither mutualism nor facilitation, and therefore further research should clarify the true impact of species interactions. Furthermore, changes in the habitat available may result in a substantial increment in the competition between species (Wisz et al., 2013). The cyprinids density partial dependence plot showed a decrement at the tail of the curve. Therefore, in spite of being uncertain, it could suggest that, under different habitat conditions than those in our study, the positive interaction with cyprinid fish species may become habitat competition, thus emphasising the necessity of close monitoring in the near future to avoid ecological loss.

\subsection{Model uncertainty}

Relatively few studies address uncertainty in ecological modelling and its effects on model predictions and decision making (Elith and Leathwick, 2009). In accordance with previous studies (Peters et al., 2009), the largest uncertainty tended to appear in the regions of the input variables that were poorly represented in the training database. In contrast to the high uncertainty demonstrated by the different MLP candidate predictions, the optimal MLP Ensembles produced sound and smoother partial dependence plots that allowed general trends to be derived from a wide range of model outputs. This has been stimulated by three approaches applied in our study. First, the bias and variance dilemma (Geman et al., 1992) was addressed by limiting model complexity (i.e. limiting the number of nodes and variables), leading to less complex models than in previous studies (Dedecker et al., 2004; Lek et al., 1996). Second, the early stop regularisation considered the errors committed on the training and validation datasets (Ludwig et al., 2014). Third and most importantly, we assessed overfitting by checking whether species responses to environmental variables were consistent with the ecological gradient theory (Austin, 2007). Inconsistent model results would have suggested a more restrictive modelling approach by limiting model complexity or adjusting the early stop parameters. Uncertainty could also arise when samples from different periods are combined, since fish density is a density-dependent phenomenon (Mas-Martî et al., 2010); however, the sampling year was not selected as an important variable in the optimal MLP Ensembles. Consequently, the results from our study suggest that temporal packing can be considered admissible when focusing on a short time span.

\section{Conclusions}

The MLP Ensembles have demonstrated satisfactory performance and generated predictions in line with the ecological gradient theory. As such, the models provide a better insight into the ecological niche of redfin barbel by complementing previous studies. We not only demonstrated that MLP Ensembles may outperform single MLPs, but also that the active selection of MLP candidates to create an optimal subset of models can 
further improve model performance. The physical habitat model confirmed the redfin barbel preference for middle-to-upper river segments, but not in higher and steeper reaches. The importance of depth confirms that redfin barbel prefer pool-type habitats, which emphasises the vulnerability of the species to reduced flows. Although the biotic model showed higher uncertainty, it suggested that redfin barbel, European eel and the considered cyprinid species have similar habitat requirements. Due to its high predictive performance and its ability to deal with model uncertainty, the MLP Ensemble paradigm is a promising tool for ecological modelling or habitat suitability prediction to assess environmental flows.

\section{References}

Alcaraz-Hernández, J.D., Martínez-Capel, F., Peredo, M., Hernández-Mascarell, A., 2011. Mesohabitat heterogeneity in four mediterranean streams of the Jucar river basin (Eastern Spain). Limnetica 30 (2), 15-363.

Aparicio, E., 2002. Ecologia del barb cua-roig (Barbus haasi) i avaluació del seu estat de conservació a Catalunya. Programa de Doctorat de Biologia Animal I - Zoologia - Bienni 1991-1993., pp. 173 (Catalan)

Aparicio, E., De Sostoa, A., 1999. Pattern of movements of adult Barbus haasi in a small Mediterranean stream. J. Fish Biol. 55 (5), 1086-1095, http://dx.doi.org/ 10.1006/jfbi.1999.1109

Araújo, M.B., New, M., 2007. Ensemble forecasting of species distributions. Trends Ecol. Evol. 22 (1), 42-47, http://dx.doi.org/10.1016/j.tree.2006.09.010

Austin, M., 2007. Species distribution models and ecological theory: a critical assessment and some possible new approaches. Ecol. Model. $200(1-2), 1-19$, http:/ dx.doi.org/10.1016/i.ecolmodel.2006,07.005

Baran, P., Lek, S., Delacoste, M., Belaud, A., 1996. Stochastic models that predict trout population density or biomass on a mesohabitat scale. Hydrobiologia 337 (1-3), 1-9, http://dx.doi.org/10.1007/BF00028502

Barve, N., Barve, V., Jiménez-Valverde, A., Lira-Noriega, A., Maher, S.P., Peterson, A.T. et al., 2011. The crucial role of the accessible area in ecological niche modeling and species distribution modeling. Ecol. Model. 222 (11), 1810-1819, http://dx. doi.org/10.1016/i.ecolmodel.2011.02.011

Bianco, P.G., 1998. Diversity of Barbinae fishes in southern Europe with description of a new genus and a new species (Cyprinidae). Ital. J. Zool. 65 (Suppl. 1), 125-136, http://dx.doi,org/10.1080/11250009809386804

Bonada, N., Rieradevall, M., Prat, N., Resh, V.H., 2006. Benthic macroinvertebrate assemblages and macrohabitat connectivity in Mediterranean-climate streams of northern California. I. N. Am. Benthol. Soc. 25 (1), 32-43, http://dx.doi.org/10. 1899/0887-3593(2006)25|32:bmaamc|2.0.co;2

Boulangeat, I., Gravel, D., Thuiller, W., 2012. Accounting for dispersal and biotic interactions to disentangle the drivers of species distributions and their abundances. Ecol. Lett. 15 (6), 584-593, http://dx.doi,org/10.1111/i.1461-0248.2012. $01772 . x$

Brosse, S., Lek, S., 2000. Modelling roach (Rutilus rutilus) microhabitat using linear and nonlinear techniques. Freshwater Biol. 44 (3), 441-452, http://dx.doi.org/ 10.1046/j.1365-2427.2000.00580.x
Brown, G., Wyatt, I., Harris, R., Yao, X., 2005. Diversity creation methods: a survey and categorisation. Inf. Fusion 6 (1), 5-20, http://dx.doi.org/10.1016/i.inffus.2004. 04.004

Buisson, L., Thuiller, W., Casajus, N., Lek, S., Grenouillet, G., 2010. Uncertainty in ensemble forecasting of species distribution. Glob. Change Biol. 16 (4), 1145-1157, http://dx.doi.org/10.1111/j.1365-2486.2009.02000.x

Cannon, A.I., 2012. monmlp: Monotone Multi-layer Perceptron Neural Network, R Package Version 1.1.2.

Crisci, C., Ghattas, B., Perera, G., 2012. A review of supervised machine learning algorithms and their applications to ecological data. Ecol. Model. 240 (0), 113-122, http://dx.doi.org/10.1016/i.ecolmodel.2012.03.001

Dedecker, A.P., Goethals, P.L.M., Gabriels, W., De Pauw, N., 2004. Optimization of Arti ficial Neural Network (ANN) model design for prediction of macroinvertebrates in the Zwalm river basin (Flanders, Belgium). Ecol. Model. 174 (1-2), 161-173, http://dx.doi.org/10.1016/i.ecolmodel.2004.01.003

Dolloff, C.A., Hankin, D.G., Reeves, G.H., 1993. Basinwide Estimation of Habitat and Fish Populations in Streams Gen. Tech. Rep. SE-83. Southeastern Forest Experiment Station, Asheville, NC, USA.

Elith, I., Leathwick, I.R., 2009. Species distribution models: ecological explanation and prediction across space and time. Ann. Rev. Ecol. Evol. Syst. 40, 677-697. http://dx.doi.org/10.1146/annurev.ecolsys.110308.120159

Ferreira, T., Oliveira, J., Caiola, N., de Sostoa, A., Casals, F., Cortes, R., et al., 2007. Ecological traits of fish assemblages from Mediterranean Europe and their responses to human disturbance. Fish. Manage. Ecol. 14(6), 473-481, http://dx.doi.org/10. 1111/j.1365-2400.2007.00584.x

Figuerola, B., Maceda-Veiga, A., de Sostoa, A., 2012. Assessing the effects of sewage effluents in a Mediterranean creek: fish population features and biotic indices Hydrobiologia 694 (1), 75-86, http://dx.doi.org/10.1007/s 10750-012-1132-y

Fox, J., 2010. polycor: Polychoric and Polyserial Correlations. R Package Version 0.7-8.

Freyhof, J., Brooks, E., 2011. European Red List of Freshwater Fishes Luxembourg. Publications Office of the European Union, Luxembourg

Friedman, J.H., 2001. Greedy function approximation: a gradient boosting machine Ann. Stat. 29 (5), 1189-1232, http://dx.doi.org/10.1214/aos/1013203451

Fukuda, S., De Baets, B., Waegeman, W., Verwaeren, J., Mouton, A.M., 2013. Habitat prediction and knowledge extraction for spawning European grayling (Thymallus thymallus L.) using a broad range of species distribution models. Environ. Model. Softw. 47, 1-6, http://dx.doi.org/10.1016/i.envsoft.2013.04.005

Fukuda, S., Mouton, A.M., De Baets, B., 2011a. Abundance versus presence/absence data for modelling fish habitat preference with a genetic Takagi-Sugeno fuzzy system. Environ. Monit. Assess. 184(10), 6159-6171, http://dx.doi.org/10.1007/ s10661-011-2410-2

Fukuda, S., De Baets, B., Mouton, A.M., Waegeman, W., Nakajima, I. Mukai, T., et al., 2011b. Effect of model formulation on the optimization of a genetic Takagi-Sugeno fuzzy system for fish habitat suitability evaluation. Ecol. Model. 222 (8). 1401-1413, http://dx.doi.org/10.1016/1.ecolmodel.2011.01.023

García de Jalón, D., Schmidt, G., 1995. Manual práctico para la gestión sostenible de la pesca fluvial. Madrid, Spain (in Spanish).

Geman, S., Bienenstock, E., Doursat, R., 1992. Neural networks and the bias/variance dilemma. Neural Comput. 4(1), 1-58, http://dx.doi.org/10.1162/neco.1992.4.1. 1

Gevrey, M., Dimopoulos, I., Lek, S., 2006. Two-way interaction of input variables in the sensitivity analys is of neural network models. Ecol. Model. 195(1-2), 43-50, http://dx.doi.org/10.1016/i.ecolmodel.2005.11.008

Grossman, G.D., De Sostoa, A., 1994. Microhabit use by fish in the upper Rio Matarrana, Spain, 1984-1987. Ecol. Freshw. Fish 3 (4), 141-152, http://dx.doi.org/10. 1111/i.1600-0633.1994.tb00016.x

Guisan, A., Thuiller, W., 2005. Predicting species distribution: offering more than simple habitat models. Ecol. Lett. 8 (9), 993-1009, http://dx.doi.org/10.1111/i. 1461-0248.2005.00792.x

Hansen, L.K., Salamon, P., 1990. Neural network ensembles. IEEE Trans. Pattern Anal. 12 (10), 993-1001, http://dx.doi.org/10.1109/34.58871

Hopkins II, R.L., Burr, B.M., 2009. Modeling freshwater fish distributions using multiscale landscape data: a case study of six narrow range endemics. Ecol. Model. 220 (17), 2024-2034, http://dx.doi.org/10.1016/j.ecolmodel.2009.04.027

Mullahy, J., 1986. Specification and testing of some modified count data models. J. Econometr 33 (3) 341-365, http:/dx doi.org/10.1016/0304-4076(86)90002-3

Jackson, C.H., 2008. Displaying uncertainty with shading. Am. Stat. 4(62), 340-347, http://dx,doi.org/10.1198/000313008X370843

Kemp, S.I.. Zaradic, P., Hansen, F., 2007. An approach for determining relative input parameter importance and significance in artificial neural networks. Ecol. Model 204 (3-4),326-334, http://dx.doi.org/10.1016/j.ecolmodel.2007.01.009

Laffaille, P., Feunteun, E., Baisez, A., Robinet, T., Acou, A., Legault, A., et al., 2003. Spatial organisation of European eel (Anguilla anguilla L.) in a small catchment. Ecol. Freshw. Fish 12 (4), 254-264, http://dx.doi.org/10.1046/i.1600-0633.2003. $00021 . x$

Lambert, D., 1992. Zero-inflated Poisson regression, with an application to defects in manufacturing. Technometrics. 34, 11-14, http://dx.doi.org/10.2307/1269547

Landa, I.T., 1998. Bioeconomics of schooling fishes: selfish fish, quasi-free riders, and other fishy tales. Environ. Biol. Fish. 53 (4), 353-364, http://dx.doi.org/10.1023/ A:1007414603324

Larocque, G.R., Mailly, D., Yue, T.-., Anand, M., Peng, C., Kazanci, C., et al., 2011. Common challenges for ecological modelling: synthesis of facilitated discussions held at the symposia organized for the 2009 conference of the Internationa Society for Ecological Modelling in Quebec City, Canada (October 6-9, 2009). Ecol. Model. 222 (14), 2456-2468, http://dx.doi.org/10.1016/j.ecolmodel.2010. 12.017 
Leathwick, I.R., Austin, M.P., 2001. Competitive interactions between tree species in New Zealand's old-growth indigenous forests. Ecology 82 (9), 2560-2573, http://dx.doi.org/10.2307/2679936

Lek, S., Delacoste, M., Baran, P., Dimopoulos, I., Lauga, I., Aulagnier, S., 1996. Application of neural networks to modelling nonlinear relationships in ecology. Ecol. Model. 90 (1), 39-52, http://dx.doi.org/10.1016/0304-3800(95)001425

Liaw, A., Wiener, M., 2002. Classification and regression by randomForest. R News 3 (2), 18-22.

Lin, X., Zhang, D., 1999. Inference in generalized additive mixed models by using smoothing splines. J. R. Stat. Soc. Ser. B: Stat. Methodol. 61 (2), 381-400, http: /I dx.doi.org/10.1111/1467-9868.00183

Liu, H., Chan, K., 2010. Introducing COZIGAM: an R package for unconstrained and constrained zero-inflated generalized additive model analysis. J. Stat. Software $35(11), 1-26$.

Ludwig, O., Nunes, U., Araujo, R., 2014. Eigenvalue decay: a new method for neu ral network regularization. Neurocomputing 124, 33-42, http://dx.doi.org/10. 1016/i.neucom.2013.08.005

Martínez-Capel, F., García De Jalón, D., Werenitzky, D., Baeza, D., Rodilla-Alamá, M., 2009. Microhabitat use by three endemic Iberian cyprinids in Mediterranean rivers (Tagus River Basin, Spain). Fish. Manage. Ecol. 16 (1), 52-60, http://dx.doi. org/10.1111/i.1365-2400.2008.00645.X

Mas-Martí, E., García-Berthou, E., Sabater, S., Tomanova, S., Muñoz, I., 2010. Compar ing fish assemblages and trophic ecology of permanent and intermittent reache in a Mediterranean stream. Hydrobiologia 657 (1), 167-180, http://dx.doi.org/ $10.1007 / \mathrm{s} 10750-010-0292-\mathrm{X}$

May, R., Dandy, G., Maier, H., 2011. Review of Input Variable Selection Meth ods for Artificial Neural Networks. In: Suzuki, K. (Ed.) Artificial Neural Networks - Methodological Advances and Biomedical Applications. InTech, p. 362 .

Miranda, R., Díez-León, M., Escala, M.C., 2005. Length relationships of cyprinid prey in diet analysis of Eurasian otter Lutra lutra in Mediterranean habitats. Folia Zool. $54(4), 443-447$

Mouton, A.M., Alcaraz-Hernández, J.D., De Baets, B., Goethals, P.L.M., Martínez-Capel, F., 2011. Data-driven fuzzy habitat suitability models for brown trout in Spanish Mediterranean rivers. Environ. Model. Softw. 26(5), 615-622, http://dx.doi.org/ $10.1016 /$ i.envsoft.2010.12.001

Mouton, A.M., De Baets, B., Goethals, P.L.M., 2010. Ecological relevance of perfor mance criteria for species distribution models. Ecol. Model. 221 (16), 1995-2002, http://dx.doi.org/10.1016/j.ecolmodel.2010.04.017

Muñoz-Mas, R., Alcaraz-Hernández, J.D., Martínez-Capel, F., 2014. Multilayer Per ceptron Ensembles (MLP Ensembles) in modelling microhabitat suitability fo freshwater fish. In: XVII Congreso Español sobre Tecnologías y Lógica Fuzzy (ESTYLF 2014), Zaragoza, Spain, pp. 609-614.

Muñoz-Mas, R., Martínez-Capel, F., Schneider, M., Mouton, A.M., 2012. Assessment of brown trout habitat suitability in the Jucar River Basin (SPAIN): comparison of data-driven approaches with fuzzy-logic models and univariate suitability curves. Sci. Total Environ. 440, 123-131, http://dx.doi.org/10.1016/j.scitotenv. 2012.07.074

Olden, J.D., Jackson, D.A., 2002. Illuminating the "black box": a randomization approach for understanding variable contributions in artificial neural networks. Ecol. Model. 154 (1-2), 135-150, http://dx.doi.org/10.1016/s0304$3800(02) 00064-9$
Olden, I.D., Lawler, I.I., Poff, N.L., 2008. Machine learning methods without tears: a primer for ecologists. Q. Rev. Biol. 83 (2), 171-193, http://dx.doi.org/10.1086/ 587826

Opitz, D.W., 1999. Feature selection for ensembles. In: Proceedings of the 1999 16th National Conference on Artificial Intelligence (AAAI-99), 11th Innovative Applications of Artificial Intelligence Conference (IAAI-99), Orlando, FL, USA, pD. 379-384.

Opitz, D.W., Shavlik, J.W., 1996. Actively searching for an effective Neural Network Ensemble. Connect. Sci. 8 (3-4), 337-353, http://dx.doi.org/10.1080/ 095400996116802

Özesmi, S.L., Tan, C.O., Özesmi, U., 2006. Methodological issues in building, training and testing artificial neural networks in ecological ap plications. Ecol. Model. 195 (1-2), 83-93, http://dx.doi.org/10.1016/i.ecolmodel.2005.11.012

Palialexis, A Georgakarakos, S. Karakassis, I, Lika, K, Valavanis, V.D., 2011. Fish distribution predictions from different points of view: comparing associative neural networks, geostatistics and regression models. Hydrobiologia 670 (1) 165-188, http://dx.doi.org/10.1007/s10750-011-0676-6

Park, Y., Chon, T., 2007. Biologically-inspired machine learning implemented to ecological informatics. Ecol. Model. 203 (1-2), 1-7, http://dx.doi.org/10.1016/ j.ecolmodel.2006.05.039

Perea, S., Garzôn, P., Gonzâlez, J. ., Almada, V. Pereira, A. Doadrio, I, 2011. New distribution data on Spanish autochthonous species of freshwater fish. Graellsia 67 (1), 91-102, http://dx.doi.org/10.3989/graellsia.2011.v67.032

Peters, I., Verhoest, N.E.C., Samson, R., Van Meirvenne, M., Cockx, L., De Baets, B., 2009. Uncertainty propagation in vegetation distribution models based on ensemble classifiers. Ecol. Model. 220(6), 791-804, http://dx.doi.org/10.1016/i.ecolmodel. 2008.12.022

R Development Core Team, 2012. R: A Language and Environment for Statistical Computing.

Soares, S., Antunes, C.H., Araújo, R., 2013. Comparison of a genetic algorithm and simulated annealing for automatic neural network ensemble development. Neurocomputing 121,498-511, http://dx.doi.org/10.1016/j.neucom.2013.05.024

Soberón, I., 2007. Grinnellian and Eltonian niches and geographic distributions of species. Ecol. Lett. 10 (12), 1115-1123, http://dx.doi.org/10.1111/j.1461-0248. 2007.01107.x

Vezza, P., Muñoz-Mas, R., Martinez-Capel, F. Mouton, A., 2015. Random forests to evaluate biotic interactions in fish distribution models. Environ. Model. Softw. 67, 173-183, http://dx.doi.org/10.1016/j.envsoft.2015.01.005

Wang, D., Alhamdoosh, M., 2013. Evolutionary extreme learning machine ensembles with size control. Neurocomputing 102,98-110, http://dx.doi.org/10.1016/ j. neucom.2011.12.046

Watts, M.I. Worner, S.P., 2008. Comparing ensemble and cascaded neural networks that combine biotic and abiotic variables to predict insect species distribution. Ecol. Inform. 3 (6), 354-366, http://dx,doi.org/10.1016/i.ecoinf.2008,08,003

Wisz, M.S., Pottier, J., Kissling, W.D., Pellissier, L., Lenoir, J., Damgaard, C.F., et al., 2013. The role of biotic interactions in shaping distributions and realised assemblages of species: implications for species distribution modelling. Biol. Rev. 88 (1), 15-30, http://dx.doi.org/10.1111/j.1469-185X.2012.00235.X

Yao, X., Xu, Y., 2006. Recent advances in evolutionary computation. J. Comput. Sci. Technol. 21 (1), 1-18, http://dx.doi.org/10.1007/s11390-006-0001-4

Zhou, Z.H., Wu, J., Tang, W., 2002. Ensembling neural networks: many could be better than all. Artif. Intell. 137 (1-2), 239-263, http://dx.doi.org/10,1016/s00043702(02)00190-X. 